Bolm Inst. oceanogr., S Paulo, 29(1):57-68, 1980

\title{
A STUDY OF THE CIRCULATION IN BAY OF ILHA GRANDE AND BAY OF SEPETIBA* \\ PART II, AN ASSESSMENT TO THE TIDALLY AND WIND-DRIVEN CIRCULATION US ING A FINITE ELEMENT NUMERICAL MODEL
}

\author{
SERGIO ROMANO SIGNORINI \\ Instituto Oceanogräfico da Universidade de São Paulo
}

Synopsis

A finite element, two-dimensional hydrodynamical numerical model developedby Wang \& White (1976) was applied to study the tidal and wind-driven crrculations in the coastal domain formed by Bay of Ilha Grande and Bay of Sepetiba. The tidal circulation was modeled by imposing a co-oscillating tidal signal at the open boundaries of the domain. The amplitude and phase of the tidal constitisnts adopted to min the numerical experiment were based on harmonic analysis of previous investigations in the region, plus data obtained from two tide gauges installed near the open boundaries of the modeled domain. The numerical simulation of the wind-driven circulation was based on wind data statistics covering 16 months of data. The effect of the wind in the local circulation was weighted by the frequency distribution of wind directions as well as the associated most probable wind forces. The numerical model was also used to simulate seiche oscillations in the coupled system formed by Bay of ITha Grande and Bay of Sepetiba. The model results are in agreement with the results derived in Part I of this paper, where field data was analysed and discussed.

\section{Introduction}

The finite element two-dimensional model developed by Wang \& White (1976) is used to assess the tidal and wind driven flows in Bay of Ilha Grande and Bay of Sepetiba. The model's governing equations are reviewed and a detailed discussion on the boundary conditions adopted is offered.

The tidal flow is modeled by driving the free-surface elevation at the ocean boundaries with a tidal signal containing tidal constituents with phases and amplitudes based on the harmonic analysis of tide gauge records.

The wind driven flow numerical experiments were performed with winds from various different directions. Their individual effects were weighed by the average frequency of occurrence for each wind direction based on the wind data discussed in Part I of this paper.

* This paper is part of a $\mathrm{Ph}$. D. Thesis submitted to the Graduated Schooi of Oceanography of the University of Rhode Island, USA.

Publ. no 484 do Inst. oceanogr. da Usp.
The model dynamics and the finite element formulation

On this two-dimensional numerical model approach, the finite element

lumped mass scheme developed by Wang \& White (1976) was used.

The lumped mass scheme is an alternative to the much slower and memory consuming consistent mass scheme.

The dynamics of the problem are described by the governing equations which derive from the we11-known Navier-Stokes equations. After vertical integration and assuming the hydrostatic approximation, the momentum equations can be written as:

$$
\begin{aligned}
& \frac{\partial \bar{u}}{\partial_{t}}+\bar{u} \frac{\partial \bar{u}}{\partial x}+\bar{v} \frac{\partial \bar{u}}{\partial y}= \\
& f \bar{v}-g \frac{\partial \eta}{\partial x}+\frac{1}{\rho H}\left(\tau_{s x}-\tau_{b x}\right) \\
& \frac{\partial \bar{v}}{\partial t}+\bar{u} \frac{\partial \bar{v}}{\partial x}+\bar{v} \frac{\partial \bar{v}}{\partial y}= \\
& -f \bar{u}-g \frac{\partial \eta}{\partial y}+\frac{1}{\rho H}\left(\tau_{s y}-\tau_{b y}\right)
\end{aligned}
$$


where

$\overline{\mathrm{u}}=\frac{1}{\mathrm{H}} \int_{-\mathrm{h}}^{\mathrm{n}} \mathrm{udz}$

$$
\bar{v}=\frac{1}{H} \int_{-h}^{n} v d z
$$

$f=$ Coriolis parameter $=2 \Omega \sin \phi$

$\eta$ = free-surface elevation

$g \frac{\partial \eta}{\partial x}, g \frac{\partial \eta}{\partial y}=\begin{aligned} & \text { horizontal pressure } \\ & \text { gradients }\end{aligned}$

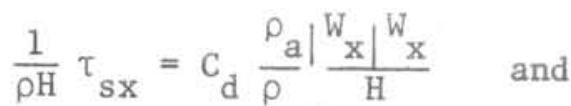

$\frac{1}{\rho H} \tau_{s y}=C_{d} \frac{\rho_{a}}{\rho} \frac{\left.W_{y}\right|^{W} y}{H}$

are the components of the wind stress expressed in the quadratic law form

$\rho=$ water density $\rho_{\mathrm{a}}=\operatorname{air}$ density

$\begin{aligned} W_{x}, W_{y}= & \text { wind velocity components } \\ & \text { (in knots) }\end{aligned}$

$\mathrm{C}_{\mathrm{d}}=$ dimensionless drag coefficient

$$
\begin{gathered}
\frac{1}{\rho \mathrm{H}} \tau_{\mathrm{bx}}=g \frac{\bar{u}\left(\bar{u}^{2}+v^{2}\right)^{1 / 2}}{\mathrm{C}^{2} \mathrm{H}} \text { and } \\
\frac{1}{\rho \mathrm{H}} \tau_{\mathrm{by}}=g \frac{\bar{v}\left(\bar{u}^{2}+\bar{v}^{2}\right)^{1 / 2}}{\mathrm{C}^{2} \mathrm{H}} \\
\mathrm{C}_{\mathrm{d}} \rho_{\mathrm{a}} / \rho=0.00564
\end{gathered}
$$

are the components of the bottom stress expressed in terms of the chezy cuefficient. An approximation for the Chezy coefficient is $\mathrm{C}=(4.65 / \mathrm{N}) \mathrm{H}^{1 / 6}$ in CGS units $\left(\mathrm{cm}^{1 / 2} / \mathrm{s}\right)$. $\mathrm{N}$ is the Manning friction factor whose value depends on the bottom roughness.

The model coordinate system is defined as

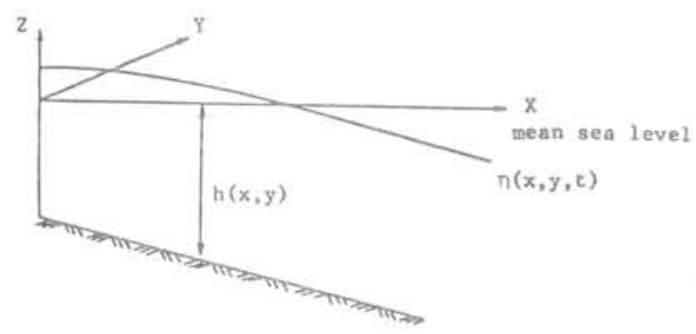

and $H(x, y, t)=n(x, v, t)+h(v, \ldots$

Continuity is expressed by wa shallow water continuity equation which has the form:

$\frac{\partial \eta}{\partial t}+\frac{\partial}{\partial x}(H \bar{u})+\frac{\partial}{\partial y}(H \bar{v})=0$

Equations (1), (2) and (3) form a set of governing equations that describe the kind of dynamics envisaged in the model, which, subjected to the proper boundary conditions and written in the finite element form can be computer coded and finally solved for the variables of interest.

\section{Boundary conditions}

Since most of the coastal problems deal with semi-enclosed domains, i.e., the boundaries of the domains consist in most of the cases, of both land and one or more connections to external bodies of water adjacent to the domain to be modeled, the boundary conditions are twofold.

First, one has to be concerned with the solid boundaries where no flux of water should be allowed normal to the direction of the boundary, and, second, the water boundaries should be assigned with the proper driving boundary conditions, which in mathematical terminology could be called forcing functions . Aside the wind stress forcing at the free surface, these driving boundary conditions are responsible for most of the circulation behaviour inside the domain and therefore should be carefully chosen and based on solid experimental field data. The knowledge of the time dependent free surface elevation along these open boundaries is extremely, important in order to get reliable and accurate model results. Fortunately, in the case of Bay of I Iha Grande, data from eight tide gauges operated by the Brazilian Navy and from two other gauges installed during the September 1977 field work sites close to the open boundaries, made the model calibration an easier task. The Navy data was furnished a1ready processed in the form of harmonic constants for 36 tidal constituents. The harmonic analysis applied to tides is a we11-known technique and it is discussed 
in most of text books dealing with tidal analysis (Dronkers, 1964). The ultimate product of this analysis is a set of constants, amplitudes and phase angles, that, together with the knowledge of the correspondent periods of the various constituents allow to synthesize the tidal signal which is as accurate as the number of constituents taken into account. A condensed form to express the tidal elevation as a function of these constants can be written as:

$$
\begin{aligned}
& H(t)=s_{0}+\sum_{n} f_{n} h_{n} \cos \\
& \left(\omega_{n} t+\left(v_{0}+u\right)_{n}-g_{n}\right)
\end{aligned}
$$

where $S_{o}$ is the mean sea level, $h_{n}$ and $g_{n}$ are the amplitude and phase angle given as a result of the harmonic analysis and are strickly connected to the location of the gauge, $f_{n}$ is the node factor, $\left(\mathrm{V}_{\mathrm{O}}+\mathrm{u}\right)_{\mathrm{n}}$ is the astronomical argument, $\omega_{\mathrm{n}}$ the constituent frequency and $t$ is the time. The summation is taken over all the $\mathrm{n}$ constituents.

A harmonic analysis prediction of the tidal elevations for Ilha Guaíba and Piraquara (the location of the tide gauges are shown in Figure 1 of Part I; Ilha Guaiba is the small island at the mouth of Bay of Sepetiba and Piraquara is near site $M$, on the northern shore of Bay of Ilha Grande) for the month of September 1977 are plotted in Figure 1. The presence of the lunar forthnightly tidal constituent is clearly shown by the modulation on the tidal signal with a period of 14 days.

Since the model was run for two tidal cycles, the very long period constituents, such as the lunar forthnightly (Mf $\simeq 14$ days), were not considered. tidal range of about $120 \mathrm{~cm}$, corresponding to the spring tide, was selected for the numerical simulation of the tidal flow. The short period constituents M2, S2 and M4 are responsible for more than $60 \%$ of the daily tidal signal, and, therefore were the ones selected to drive the tidal flow.

Figure 2 shows the grid system adopted to represent the geometry of the region. The domain is connected to the ocean by two open boundaries. The two tide gauges nearest to these open boundaries (see Fig. 17 in Part I) show no apparent phase lag, leading to the conclusion that the cotidal lines must approach the coast parallel to the open boundaries. However, since there was no tide gauge installed at the open boundaries themselves, some test runs with different phase lags were performed in order to find a best fit to the experimental data available. The best results were achieved when no phase lag between the two open boundaries was adopted.

\section{Numerical stability}

The maximum time step allowable for a stable numerical integration is limited by the constraint that a shallow water gravity wave such as the propagating tides must travel freely throughout the discretized domain with a phase velocity given by $c_{p}=(g h)^{1 / 2}$, where $g$ is the acceleration due to gravity and $\mathrm{h}$ is the water depth. Therefore, the maximum time step will be a function of the grid size and the shallow water wave phase velocity, i.e.,

$$
\left(t=\gamma\left(\Delta x /(g h)^{1 / 2}\right)\right.
$$

where $\mathrm{t}$ is the time step, $\Delta \mathrm{x}$ is the minimum grid size associated with the maximum depth, and $\gamma$ is a constant.

However, in order to achieve stable numerical results, the stability constraints cannot be based on the physical constraints alone and numerical stabili= ty tests in the past have shown that the value of the dimensionless constant $\gamma$ is less than unity.

The constant $\gamma$, which is a dimensionless measure of the size of the time step, is a function of the type of numerical scheme used and is commonly known as the Courant number. Thacker $(1978 a, b)$, used both an explicit finite difference scheme and an implicit finite element scheme to solve one-dimensional waves in a shallow channel. For stable numerical results, he showed that the Courant number for the finite difference scheme was less than 1 and for the finite element scheme less than $1 /(3)^{1 / 2}$.

Grammeltvedt (1969), on a survey of finite difference schemes for the primitive equations for a barotropic fluid, showed that for numerical stability $\gamma$ should be $1 /(2)^{1 / 2}$. This latter result was also adopted for tidal circulation problems using the finite element scheme by many investigators (Wang \& White, 1976; Brebbia, 1975; Wang, 1975) and was also adopted in this study. 


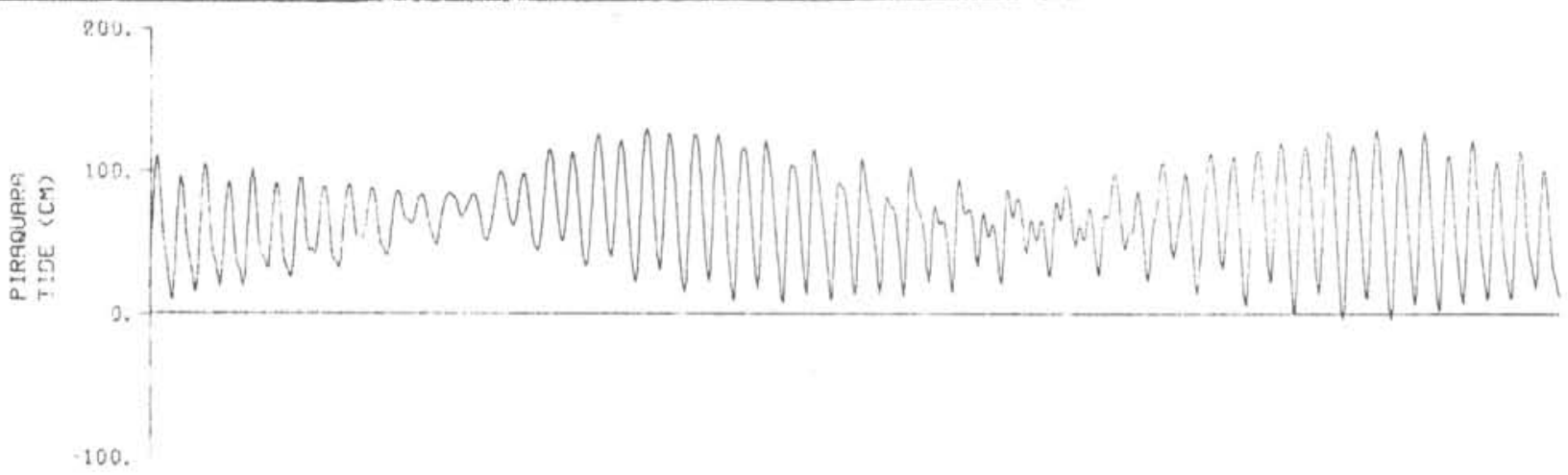

200.

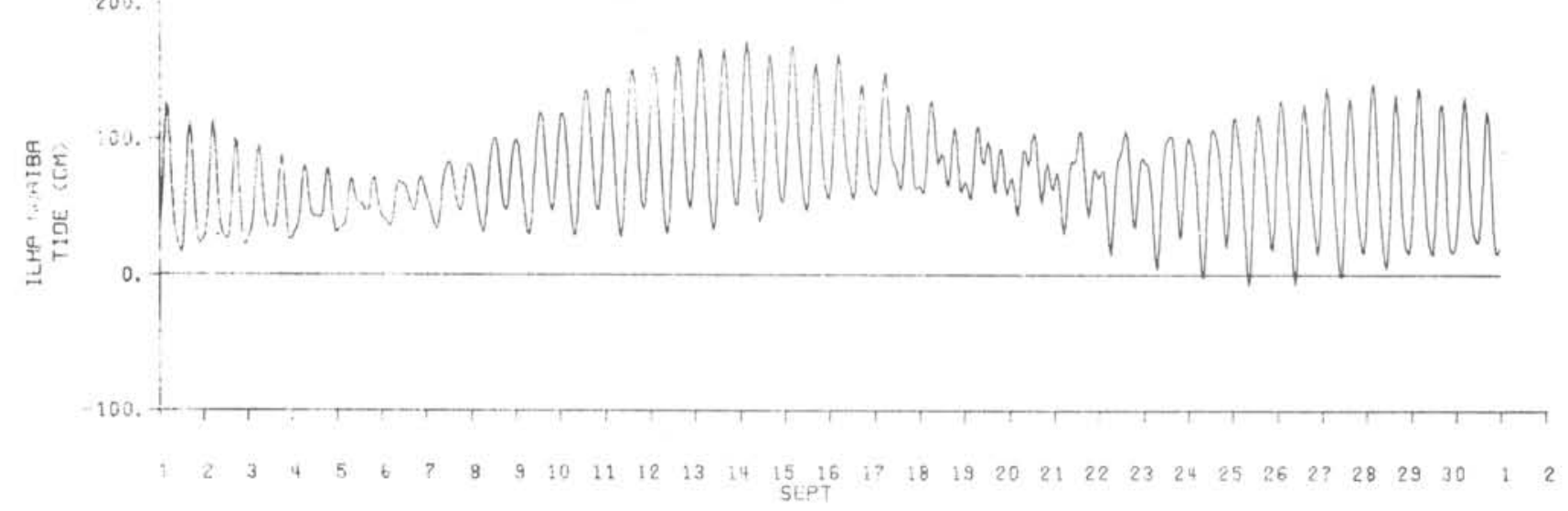

Fig. 1. Plot of the tidal elevation for the month of September 1977 at 1 lha Guaíba and Piraquara. These tidal signals were produced by means of harmonic analysis.

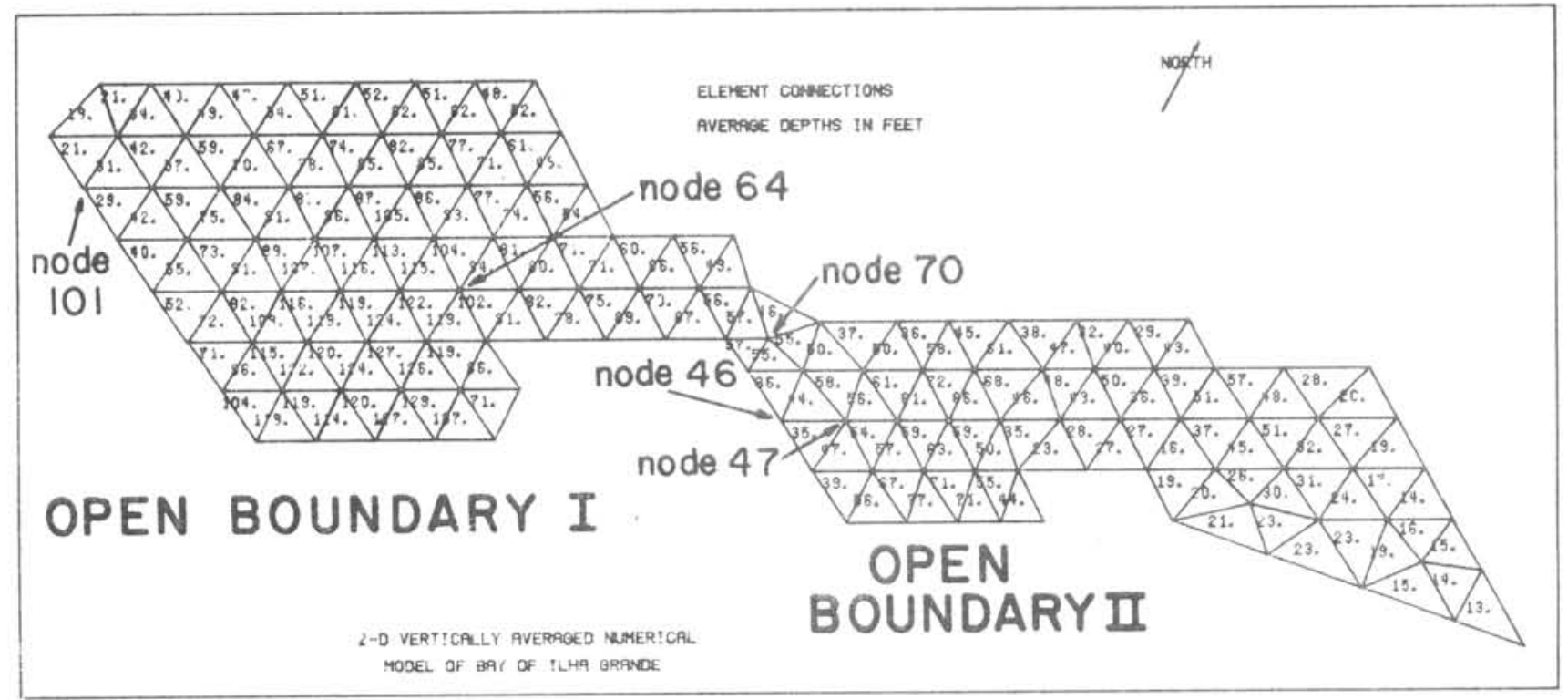

Fig. 2. The grid system adopted in the numerical studies. The system consists of 189 elements connected by 126 nodes. 


\section{Model Application - Tidal flow}

Figure 2 illustrates the grid system used to represent the model domain. It consists of 189 triangular elements and 126 nodes. The node depths were taken from the Hydrographic Office of the Brazilian Navy nautical chart number 1609 updated in 1977.

Although the grid system could be more refined, especially in Bay of Sepetiba (eastern side) where small islands were neglected due to the large size of the grid, it represents roughly the major characteristics of the tidal circulation in a economical way, i.e., using the least computer time without sacrificing much of the general circulation features. More accurate results can be easily achieved by refining the grid system at points where the coastal geometry or the bathymetry makes it necessary. However, even with this nonrefined grid system, the model results agreed reasonably well with the experimental data.

The first numerical experiment was a model with a co-oscillating tidal signal driving the open boundaries and zero wind stress at the free-surface. The model parameters can be summarized in the following table:

average grid size $=3.5 \mathrm{~km}$

maximum depth $=48$ meters

minimum depth $=4$ meters

time step $=120$ seconds

simulation time $=24.84$ hours $=2$ tidal cycles

CPU time $=3.77$ minutes

amplitude and phase of tidal constituents for both open boundaries:

M2 $(12.42$ hours $)=37 \mathrm{~cm}$ and $74^{\circ}$

S2 $(12.00$ hours $)=22 \mathrm{~cm}$ and $75^{\circ}$

M4 $(6.21$ hours $)=19 \mathrm{~cm}$ and $93^{\circ}$

Manning coefficient $=0.03$

As initial conditions, the freesurface elevation and the velocity components were all set to zero. This condition is usually referred to as the "cold start".

Figure 3 shows the current roses due to the tides alone plotted over a whole tidal cycle at the center of selected elements of the grid system.

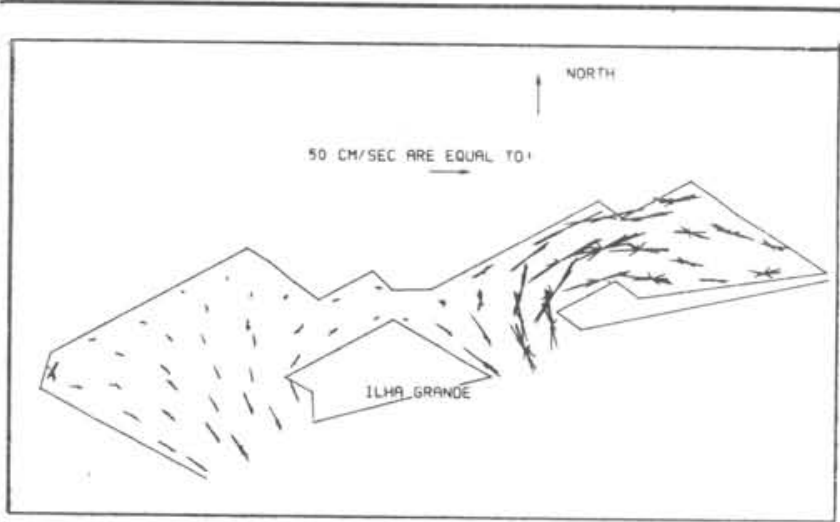

Fig. 3. Computer plot of the current roses for hourly vectors throughout a whole tidal cycle. In this experiment only tidal forcing was considered.

From Figure 3, a few results can be drawn. First, the circulation on the eastern side of Bay of Ilha Grande and inside Bay of Sepetiba is much stronger than the western side of the region. The difference is marked by currents of the order of $50 \mathrm{~cm} / \mathrm{s}$ at the race in Bay of Sepetiba as opposed to only a few centimeters per secunc in the western side of Bay of Ilha frande. Second, the exchange of water betwcen the two basins is very weak.

This means that if the Bay was driven by the co-oscillating tides alone, the two basins would exchange very little water. This contrast between the tidal signatures in the two Bays agrees with the observational data discussed in Part I.

Figure 4 shows the time series of the

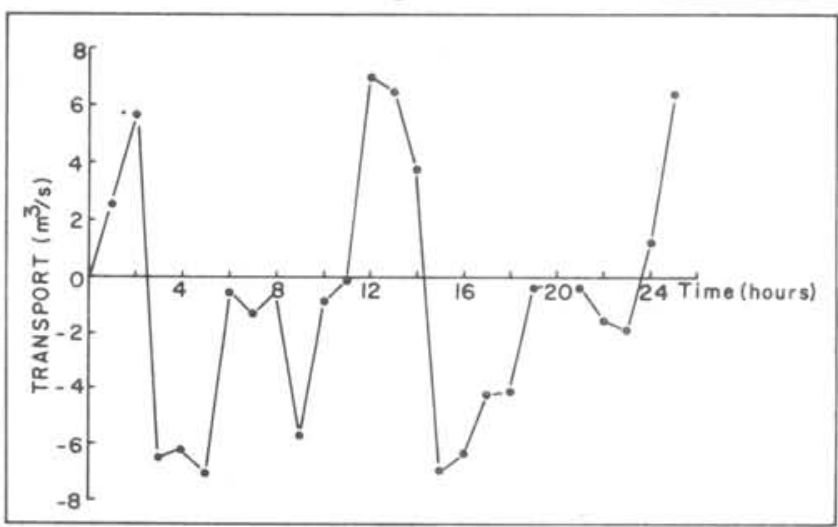

Fig. 4. Time series of the cotal transport due to the tides through the channel between IIha Grande and the coast computed from the two-dimensional numerical model results. 
total volume transport due to the tides through the channel between Ilha Grande and the coast computed from the two-dimensional numerical model results.

Although the transport oscillates between $+7000 \mathrm{~m}^{3} / \mathrm{s}$ (eastward) and $-7000 \mathrm{~m}^{3} / \mathrm{s}$ (westward), the average transport is only $-820 \mathrm{~m}^{3} / \mathrm{s}$ and it would be much less if more tidal cycles were included in the computation of the mean since many frequency components contribute to the tidal transport.

In order to verify the influence of the phase lag between the two open boundaries on the tidal circulation in Bay of Ilha Grande, a numerical sensitivity test was performed.

The previous numerical simulation of the tidally driven flow, with both open boundaries in phase, has shown that the flow through the channel between Ilha Grande and the coast was very weak ( 4 to $5 \mathrm{~cm} / \mathrm{s}$ ) and Bay of Itha Grande and Bay of Sepetiba behaved like two separate bodies of water. This is in agreement with the current meter data which showed no alternating flow with tidal signature at that point.

Two more computer runc were performed. The tidal range was $\mu_{p}$ - the same in both numerical experiments but in one case the high tide on the western open boundary led the high tide on the eastern open boundary by 20 minutes, and, in the other case the reverse problem was considered.

The computer plots for the current roses throughout a whole tidal cycle for both cases are shown in Figures 5 and 6 . The circulation pattern in Bay of Ilha Grande and Bay of Sepetiba did not change much but in both cases there is a substantial alternating tidal flow in the channel between the two Bays of the order of $20 \mathrm{~cm} / \mathrm{s}$, a flow about 4 times stronger than the flow found in the numerical simulation with no phase lag between the two boundaries. Therefore, since the case with no phase lag agrees much better with the data, it seems reasonable to assume that that is the real situation in Bay of Ilha Grande.

Conversely, the tide records taken during the field work, one at Parati and one at Abrão (see Figure 17 in Part I) were compared to the model's tidal elevation at nodes fairly close to the location of the tidal gauges. These are shown in Figure 7. Considering the coarse grid system used in this application and the

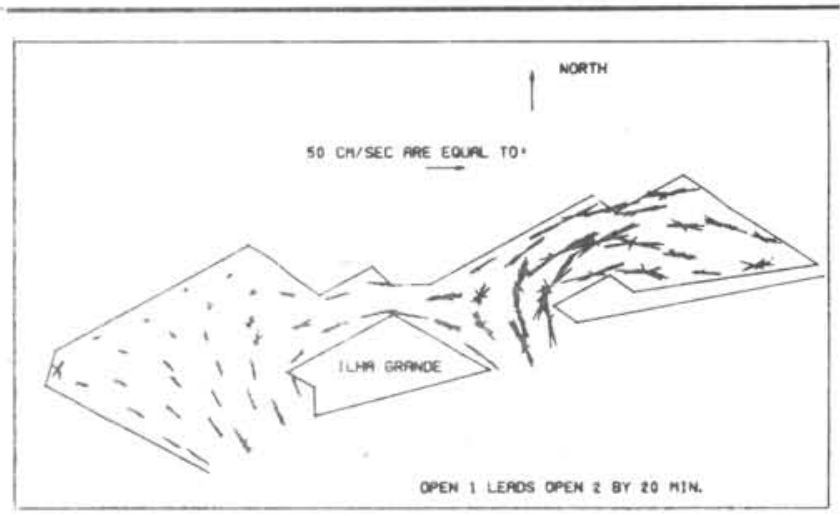

Fig. 5. Computer plot of the current roses for hourly vectors throughout a whole tidal cycle. In this case the high tide on the western open boundary leads the high tide on the eastern open boundary by 20 minutes.

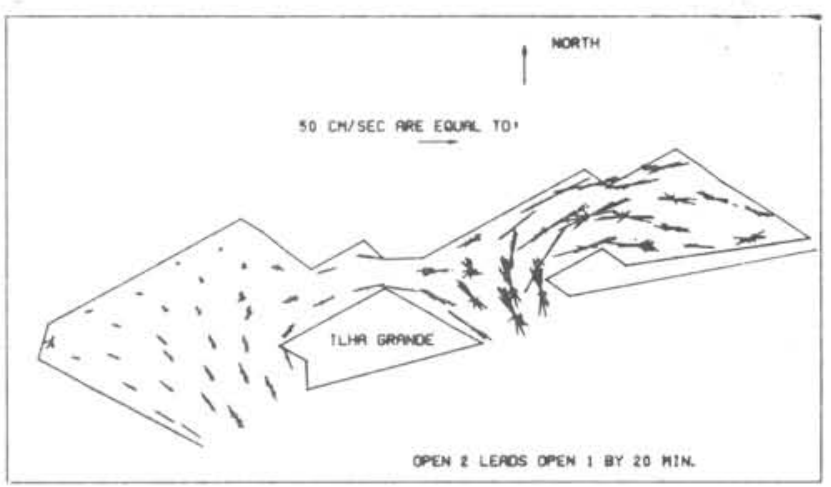

Fig. 6. Computer plot of the current roses for hourly vectors throughout a whole tidal cycle. In this case the high tide on the eastern open boundary leads the high tide on the western open boundary by 20 minutes.

limited number of constituents employed to run the mode1 (M2, S2, and M4), the agreement seems to be fairly good.

Model application - Wind driven flow

In this numerical experiment the wind driven circulation is analysed for twelve different wind directions evenly distributed in a11 quadrants.

The wind data presented in Part I have shown that the most probable wind force for the region lies between 6 and 10 knots for a11 wind directions, therefore, al1 numerical experiments were done with a wind force of 10 knots. A wind duration of twelve hours was chosen for all experiments, but the relative 

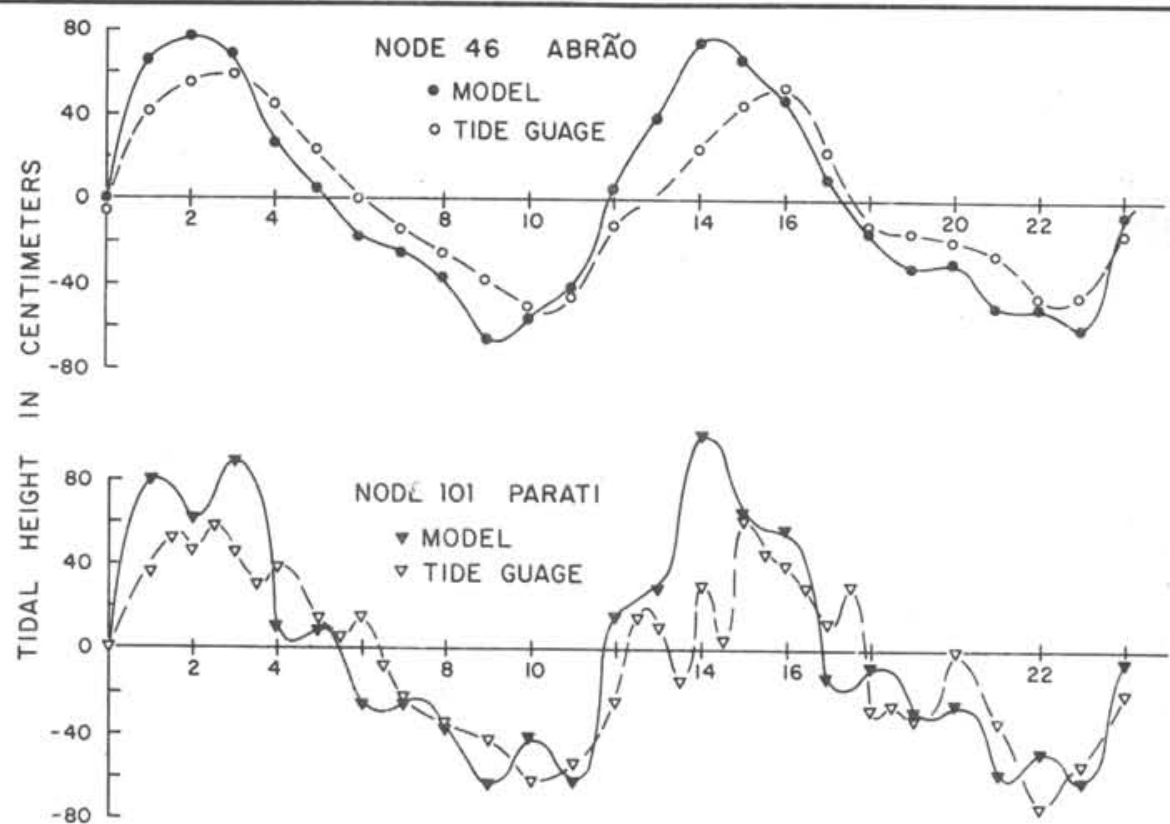

Fig. 7. Comparison between the tidal elevation given by data from two tide gauges, one at Parati and one at Abrão (see Figure 1 in Part 1), and the two-dimensional model prediction for nodal points close to the gauge locations.

effects of each wind direction were later. weighted by the frequency of occurrence for each wind direction, also based on the wind data presented in Part I.

Figures 8 and 9 show the computer plots of the wind driven flow for the most effective wind directions, i.e., the ones that promote the strongest flows; the $70^{\circ}$ (westward flow) and $250^{\circ}$ (eastward flow) winds. This may be related to the fact that these are the winds parallel to the longest dimension of the region and therefore have the longest fetch.

The total volume transport through the channel formed between Ilha Grande and the coast was computed for each wind direction as a measure of the strength of the wind driven flows, as shown in Figure 10. The most effective winds again are the $70^{\circ}$ wind, with an westward transport of $-10920 \mathrm{~m}^{3} / \mathrm{s}$, and the $250^{\circ}$ wind, with and eastward transport of $+10960 \mathrm{~m}^{3} / \mathrm{s}$. A numerical integration of the transport function of Figure 10 was performed leading to a zero mean transport, an indication of the symmetric effects by winds of opposing directions.

However, the relative effect of each

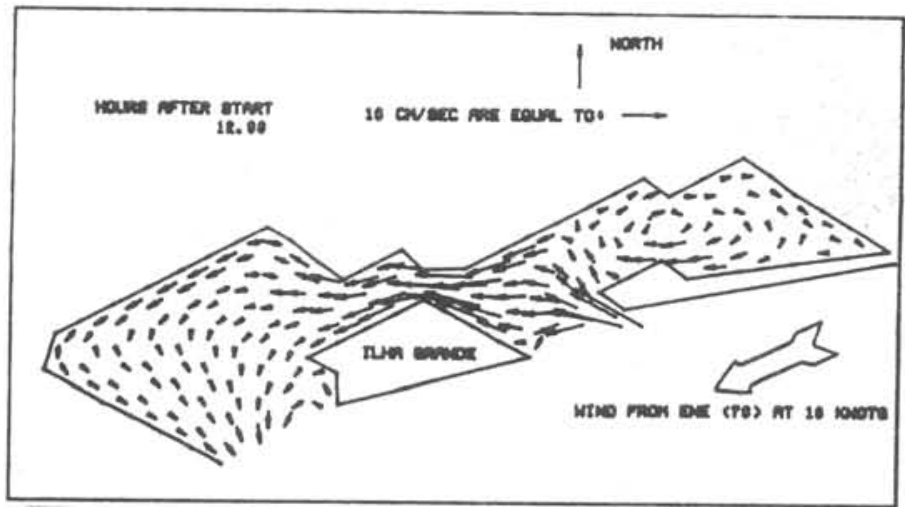

Fig. 8. Computer plot of the wind driven flow after a 12-hour simulation with a $70^{\circ}$ wind blowing at 10 knots. 


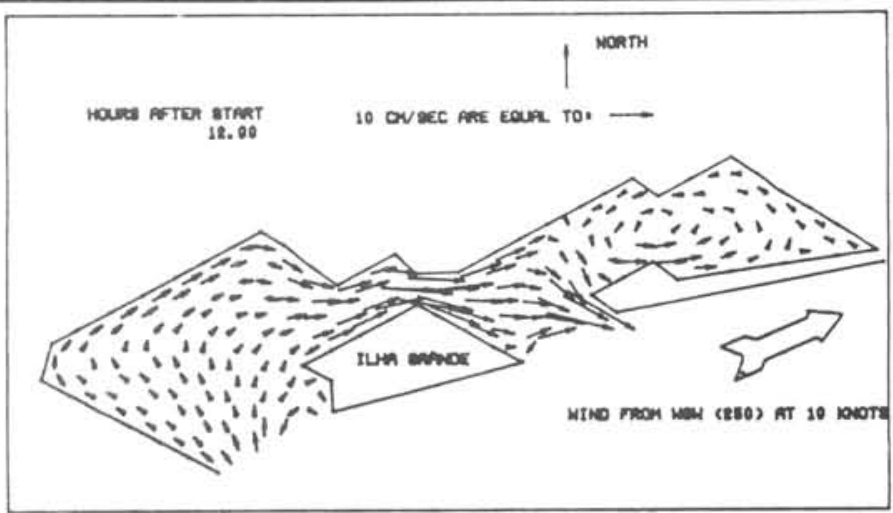

Fig. 9. Same as in Figure 8 except for the wind direction. $250^{\circ}$ wind at 10 knots.

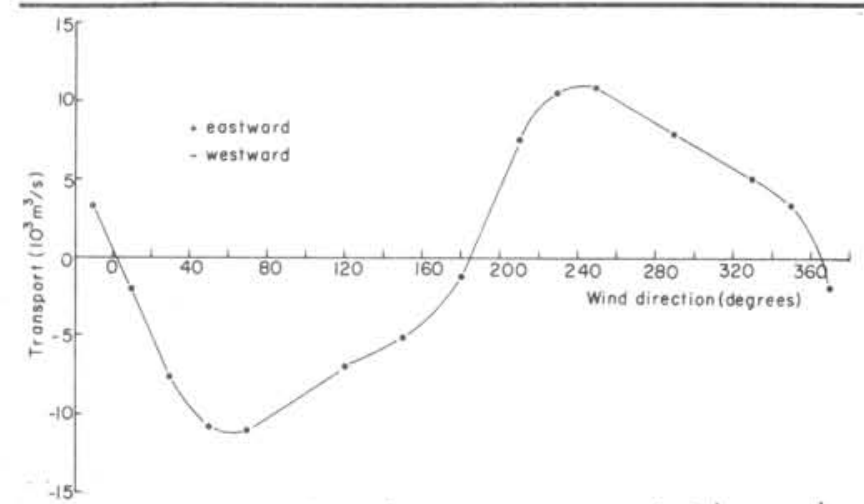

Fig. 10. Total volume transport through the channel between I lha Grande and the coast as a function of the wind direction.

wind direction has to be weighed by its frequency of occurrence, as shown by the 16 month average plot of Figure 16 in Part I. Since the data also shows that the calm condition occurs, on the average, $33 \%$ of the time, the total sum of wind frequencies should add up to $67 \%$. However, some wind directions with very low frequency of occurrence were not included in the numerical experiments and therefore they only add up to $60.2 \%$. The $6.8 \%$ difference will be accounted for by multiplying the wind frequencies by a scale factor in order to obtain the total of $67 \%$. This new wind frequency will be called the relative wind frequency and the total transports weighed by these relative frequencies of occurrence will be called the relative transports.

The total transports through the channel for each wind direction and the relative transports, obtained through the product of the relative frequencies of occurrence times the total transports, are shown in Table I. The $50^{\circ}$ wind, which occurs $7.8 \%$ of the time, and the $210^{\circ}$ wind, which occurs $18.4 \%$ of the time, are the two most probable winds, and as such, produce the largest volume transports $\left(-820 \mathrm{~m}^{3} / \mathrm{s}\right.$ and $+1380 \mathrm{~m}^{3} / \mathrm{s}$, respectively).

The net relative transport is obtained by adding the weighted transports for each wind direction. The result is $+1200 \mathrm{~m}^{3} / \mathrm{s}$, which is a good estimate of the net yearly transport through the channel, since the wind data is based on an average over a year and four months of observations .

\section{Momentum balance}

In order to assess the momentum balance in the region under study, the individual values of each term in the momentum equations were printed out from a computer run involving the $250^{\circ}$ wind and tidal forcing.

Tables II and III show the values for the momentum terms for every hour of the second tidal cycle. The major momentum balance is obviously between the time derivative (local acceleration) term and the pressure gradiente term, an indication of the presence of oscillations taking place near the finite element selected in this assessment (the element lies on the western side of the channel formed between Ilha Grande and the coast). In fact, seiches with periods between one and two hours were found on the current meter data discussed in Part 1. On the other hand, the nonlinear terms are at least two orders of magnitude smaller than the two terms involved in the major momentum balance, and about one order of magnitude smaller than the Coriolis force term. The longitudinal wind stress term $\left(\tau_{s x}\right)$ is of the same order of magnitude as the Coriolis force terms. 
Table I - Frequencies of wind occurrence and corresponding volume transports through the channel between IIha Grande and the coast

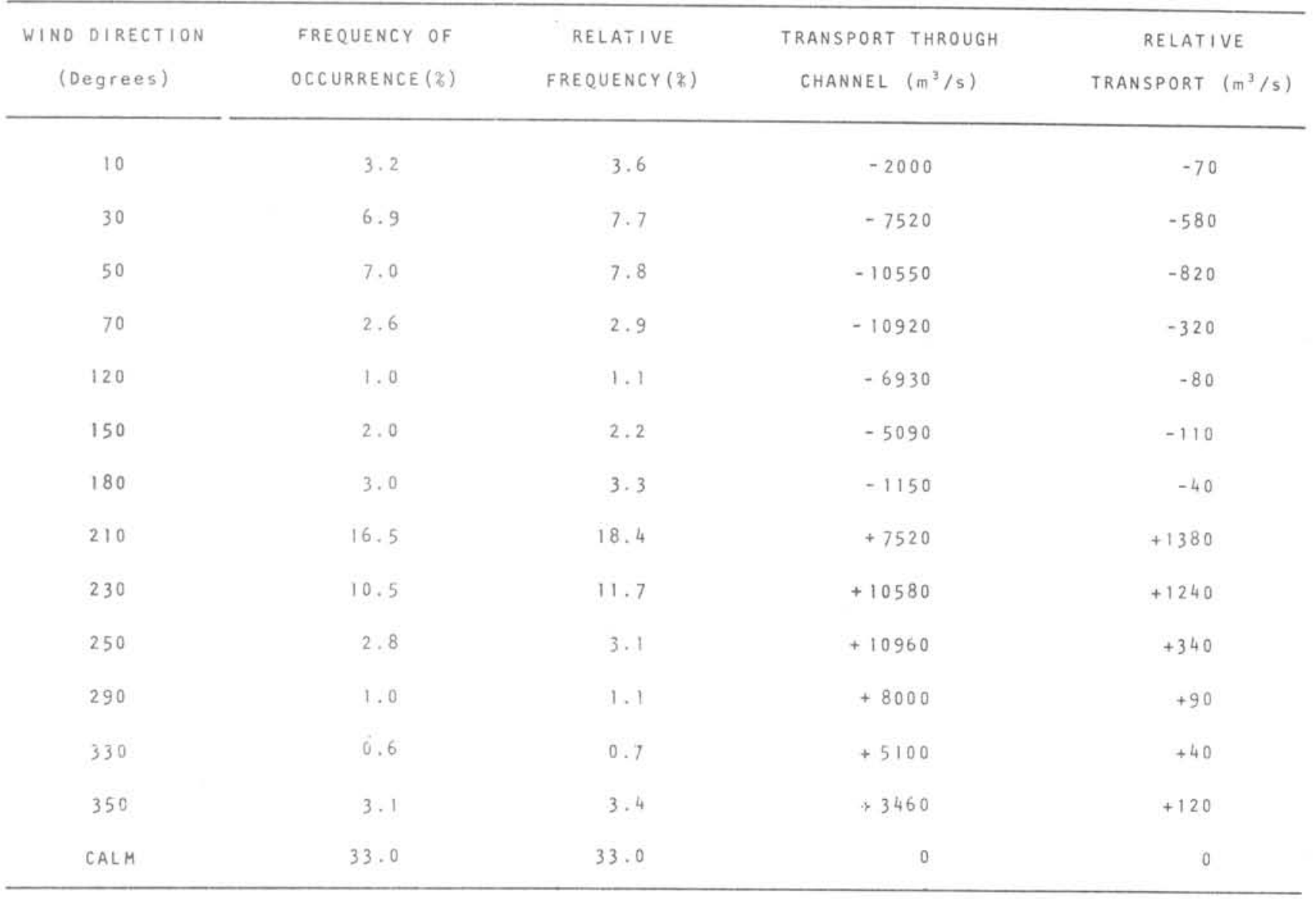

The Manning factor, or bottom roughness factor, used to compute the bottom stress in this numerical simulation is 0.03 . The typical range for the Manning factor for the numerical modeling of coastal regions is 0.025 to 0.035 . Changing the Manning factor from one extreme of the range to the other would mean a doubling of the bottom stress. The largest values of the bottom stress in Table II are about two orders of magnitude smaller than the pressure gradient and the time derivative, which means that even if one doubles the bottom stress the results would only change within one percent.

In shallower areas, like in Bay of Sepetiba for instance, the doubling of the bottom stress could change the computations of the time derivative, and therefore the velocity, by as much as $10 \%$. However, the range of the tidal velocities in Bay of Sepetiba agrees with the current meter data within $1 \%$, which indicates that the chosen value for the Manning factor (0.03) is adequate.

The Rossby number $\left(R_{O}\right)$, a measure of the magnitude of the non-linear acceleration compared to the Coriolis force, was computed for each hour using the values of Tables II and III. The average Rossby number computed this way is 0.2 .

Another way of computing the Rossby number is by forming the ratio of the characteristic scales for the acceleration and the Coriolis force terms $\left(U^{2} / L\right) / f U$, or $R_{O}=U / f L$. In Bay of Ilha Grande, the characteristic scales are $U=10 \mathrm{~cm} / \mathrm{s}, f=5.7 \times 10^{-5} \mathrm{~s}^{-1}$ and $\mathrm{L}=10 \mathrm{~km}$, which lead to a Rossby number of 0.17 , a very close value to the one obtained through the numerical model results.

Since the non-linear terms are small compared to the other momentum terms, it seems unlikely that strong non-1inear interactions between wind driven and tidally driven flows could take place in Bay of Ilha Grande. Therefore, wind and 
Table $\|$ - Balance of momentum terms in the $X$ direction with the model being driven by tides and wind from the west-southwest $\left(250^{\circ}\right)$ at 10 knots

\begin{tabular}{|c|c|c|c|c|c|c|c|}
\hline \multirow[b]{2}{*}{ TIME (hrs) } & \multirow[b]{2}{*}{$\partial u / \partial t$} & \multicolumn{4}{|c|}{$\left(\mathrm{cm} / \mathrm{s}^{2} \times 10^{4}\right)$} & \multirow[b]{2}{*}{$-1 / 0 H \tau_{s x}$} & \multirow[b]{2}{*}{$1 / \rho H \tau_{b x}$} \\
\hline & & $(u \partial u / \partial x$ & $+v \partial u / \partial y)$ & $-f v$ & $1 / \rho \partial p / \partial x$ & & \\
\hline 12 & -71.6 & & $-2 \cdot 3$ & 0.004 & 74.7 & -2.3 & 1.5 \\
\hline 13 & -97.9 & & -0.89 & 0.81 & 98.2 & -2.3 & 2.0 \\
\hline 14 & 27.4 & & 0.45 & -2.5 & -23.5 & -2.3 & 0.34 \\
\hline 15 & -56.3 & & 0.40 & -0.18 & 58.2 & $-2 \cdot 3$ & 0.09 \\
\hline 16 & -17.8 & & -1.1 & -2.0 & 23.4 & $-2 \cdot 3$ & -0.25 \\
\hline 17 & 192.6 & & -0.52 & $-1 \cdot 2$ & -188.5 & $-2 \cdot 3$ & -0.12 \\
\hline 18 & -87.3 & & -0.31 & -1.8 & 91.6 & -2.3 & 0.10 \\
\hline 19 & -102.7 & & -0.36 & -2.6 & 107.8 & $-2 \cdot 3$ & 0.12 \\
\hline 20 & 33.6 & & 0.56 & -0.79 & -31.4 & $-2 \cdot 3$ & 0.22 \\
\hline 21 & -68.1 & . & -0.31 & -1.1 & 71.8 & -2.3 & 0.08 \\
\hline 22 & 96.1 & & -0.55 & -1.1 & -92.4 & $-2 \cdot 3$ & 0.31 \\
\hline 23 & -67.2 & & 0.23 & -2.3 & 71.3 & $-2 \cdot 3$ & 0.33 \\
\hline 24 & 59.0 & & -0.64 & -0.006 & -57.9 & $-2 \cdot 3$ & 1.8 \\
\hline
\end{tabular}

tidal flows can be treated separately.

Numerical experiment on seiches

In Part I of this paper, the observational data have shown oscillations with a period of approximately 6 hours in the channel connecting the western and eastern sides of Bay of Ilha Grande. The period of these oscillations is much larger than the seiche period of either basin and an explanation was offered based on the theory developed by Neumann \& Pierson Jr. (1966). The mode of the proposed theory considers the coupled system of Bay of I1ha Grande and Bay of Sepetiba connected by a channel oscillating in a coupled way, i.e., while the water level in Bay of Ilha Grande rises, the water level in Bay of Sepetiba sinks and vice versa.

The scope of the numerical experiment in this section is to verify the existance of such mode in the region. The same two-dimensional numerical model (Wang, 1975), previous1y used in the tidal and wind-driven experiments, will be used in this numerical experiment. The grid system adopted is that of Figure 2 , with the two ocean boundaries closed since the effect of these boundaries on the longitudinal seiche mode is assumed to be negligible. The longitudinal mode is excited by specifying an initial slope to the free-surface $(n)$ and letting it free-oscillate throughout the computer run.

Initially, the free-surface elevation is specified as a linear function of the $X$ coordinate running along the longest dimension of the region.

$$
n(x)=n_{0}-\alpha x
$$

where $\eta_{0}=1.8$ meters and $\alpha=1.7 \times 10^{-5}$

Both components of the velocity are zero initially and the Manning factor, or bottom roughness coefficient, adopted was 0.01 . The model ran for 24 real hours using a time step of 120 seconds, and the results were printed out every 
Table 111 - Balance of momentum terms in the $Y$ direction with the model being by tides and wind from the west-southwest $\left(250^{\circ}\right)$ at 10 knots

\begin{tabular}{|c|c|c|c|c|c|c|c|}
\hline \multirow[b]{2}{*}{ TIME (hrs) } & \multirow[b]{2}{*}{$\partial v / \partial t$} & \multicolumn{4}{|c|}{$\left(\mathrm{cm} / \mathrm{s}^{2} \times 10^{4}\right)$} & \multirow[b]{2}{*}{$-1 / \rho H \tau_{S y}$} & \multirow[b]{2}{*}{$1 / p H \tau_{b y}$} \\
\hline & & $(u \partial v / \partial x+$ & $v \partial v / 2 y)$ & $f u$ & $1 / \rho \partial p / \partial y$ & & \\
\hline 12 & 222.6 & -1.0 & & -5.7 & -215.9 & 0.05 & 0.001 \\
\hline 13 & 9.0 & -1.6 & & -6.6 & -1.2 & 0.05 & 0.24 \\
\hline 14 & -22.7 & -0.33 & 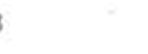 & -2.3 & 25.6 & 0.05 & -0.38 \\
\hline 15 & -270.0 & 0.27 & & -1.4 & 271.1 & 0.05 & -0.01 \\
\hline 16 & -77.8 & 0.17 & & 2.0 & 75.8 & 0.05 & -0.25 \\
\hline 17 & 95.1 & 0.05 & & 1.4 & -96.5 & 0.05 & -0.1 \\
\hline 18 & 101.7 & 0.32 & & -1.0 & -100.9 & 0.05 & -0.18 \\
\hline 19 & -31.2 & 0.05 & & -0.95 & 32.4 & 0.05 & -0.33 \\
\hline 20 & -97.6 & 0.39 & & -2.1 & 99.3 & 0.05 & -0.84 \\
\hline 21 & -278.6 & 0.08 & & -1.0 & 279.6 & 0.05 & -0.08 \\
\hline 22 & $2 y 3.4$ & -0.35 & & -2.4 & $-290 \cdot 5$ & 0.05 & -0.14 \\
\hline 23 & 140.1 & 0.25 & & -2.2 & -137.9 & 0.05 & -0.34 \\
\hline 24 & -65.4 & -0.65 & & $-6 \cdot 3$ & $72 \cdot 3$ & 0.05 & -0.002 \\
\hline
\end{tabular}

10 minutes.

Figure 11 shows the plot for the $U$ and $\mathrm{V}$ components for node number 70 , located at the center of the channel. The period of oscillation is very close to 6 hours, in agreement with both obser- vational data and the proposed theoretical mode discussed in Part I.

\section{Summary}

An assessment to the tidal and wind driven portions of the circulation in

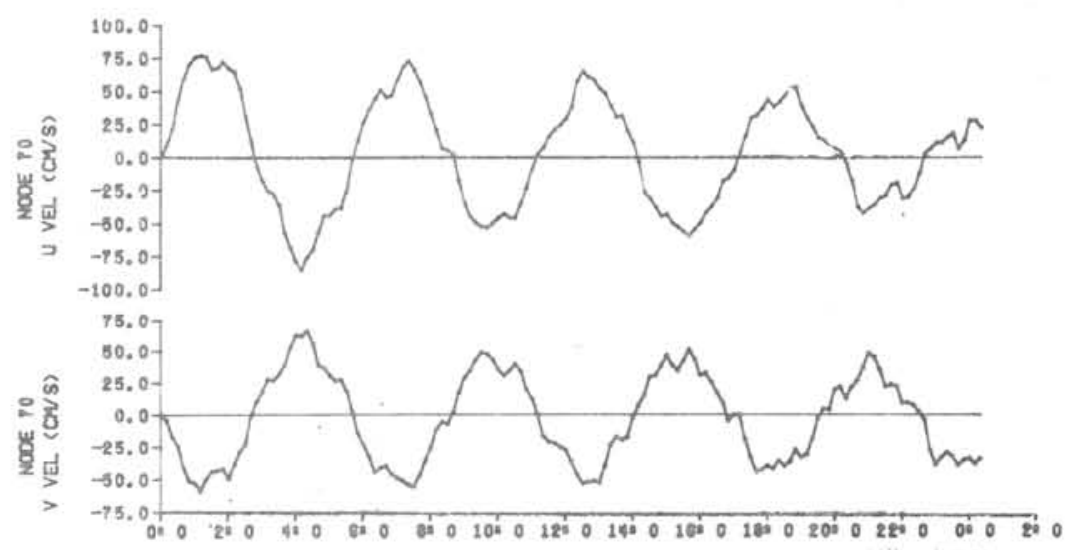

Fig. 11. Computer plot of the two components of the velocity for node 70 (located at the center of the channel) showing the period of the seiche mode for the coupled system of Bay of I Tha Grande and Bay of Sepetiba. 
Bay of Itha Grande and Bay of Sepetiba was carried out using Wang \& White's mode1. The tidal flow on the eastern side of Bay of Itha Grande and inside Bay of Sepetiba is characterized by strong alternating currents of the order of $50 \mathrm{~cm} / \mathrm{s}$ as opposed to only a few centimeters per second on the western side of Bay of Ilha Grande. This contrast between the tidal signature in the two Bays agrees with the observational data.

The wind driven flow was modeled for twelve different wind directions evenly distributed in al1 quadrants. The strength of the wind driven flow for each individual wind direction was measured by the total volume transport through the channel formed between I Iha Grande and the coast. The overall effect of the wind driven flow was obtained by weighing the transports for each wind direction with the respective frequencies of occurrence derived from the yearly averaged observational wind data. The net yearly transport was estimated at $1200 \mathrm{~m}^{3} / \mathrm{s}$ in the eastward direction.

A seiche numerical experiment, involving the coupled system formed by Bay of Ilha Grande and Bay of Sepetiba, was performed by initially prescribing a linear free-surface tilt along the longest dimension of the region. The period of the free-oscillations obtained was close to 6 hours, the same period found both in the observational data and in the theoretical prediction discussed in Part $I$.

\section{References}

BREBBIA, C. A. 1975. Finite element models for coastal engineering. In: Ferrante, A. J. \& Franco, J. S. G., ed. - Curso de pós-graduação em en- genharia civil UFRGS - Seminārio abril 23-25, 1975. Porto Alegre, Univ. Fed. Rio Grande do Sul, p.J3-J36.

DRONKERS, J. J. 1964. Tidal computations in rivers and coastal waters. Amsterdam, North-Holland, 518p.

GRAMMELTVEDT, A. 1969. A survey of finite difference schemes for the primitive equations for a barotropic fluid. Mon. Weath. Rev. U.S. Dep. Agric., 97:384-404.

NEUMANN, G. \& PIERSON JR., W. J. 1966. Principles of physical oceanography. Englewood Cliffs, N. J., PrenticeHal1, 545p.

THACKER, W. C. 1978a. Comparison of finite-element and finite-difference schemes, Part I: One dimensional gravity wave motion. J. phys. Oceanogr., 8:676-679.

1978b. Comparison of finite-element and finite-difference schemes, Part II: Two dimensional gravity wave motion. J. phys. Oceanogr., 8:680-689.

WANG, H. P. 1975. Modeling an ocean pond: a two-dimensional, finite hydrodynamic model of Minigret Pond, Charlestown, Rhode Island. Mar. tech. Rep. Univ. Rhode Island, (40):1-60.

\& WHITE, F. M. 1976. Multileveled finite element hydrodynamic model of Block Island Sound. University of Rhode Island, Department of Mechanical Engineering and Applied Mechanics, 152p.

(Received in 29/Apri1/1980) 